\title{
AVALIAÇÃO DAS PROPRIEDADES FÍSICO-QUÍMICAS E DA PERMEABILIDADE AO VAPOR D'ÁGUA DE BIOFILMES À BASE DE GELATINA USANDO GLICEROL COMO PLASTIFICANTE
}

\author{
P. B. RIBEIRO ${ }^{1 *}$, R. C. ALVES $^{1}$, L. P. RICARDO ${ }^{1}$, M. M. MORAIS ${ }^{1}$ e G. S. ROSA ${ }^{1}$ \\ ${ }^{1}$ Universidade Federal do Pampa, Curso de Engenharia Química \\ *e-mail: pri.baruffi@gmail.com
}

\begin{abstract}
RESUMO
A maior parte dos alimentos está sujeita a deterioração oxidativa e microbiológica, além do desgaste mecânico. A função das embalagens alimentares é, portanto, proporcionar barreiras físicas, químicas e microbiológicas, aumentando seu tempo de prateleira. A maioria das embalagens comumente utilizadas são sintéticas, derivadas de origem petroquímica e apresentam alta estabilidade estrutural. Do ponto de vista ambiental tornam-se um problema, devido à poluição gerada por seu descarte. Dessa forma, os biofilmes surgem como alternativa às embalagens tradicionais, podendo ser compostos por biopolímeros como, por exemplo, proteínas. O presente trabalho teve por objetivo avaliar as propriedades físico-químicas de biofilmes de gelatina e glicerol a partir de análises de espessura, permeabilidade ao vapor d'água (PVA) e de Espectroscopia de Infravermelho com Transformada de Fourier (FTIR) por meio da técnica de Refletância Total Atenuada (ATR). Os resultados de análise de espessura demonstraram que a metodologia de elaboração dos filmes foi adequada e os de PVA, que os biofilmes de gelatina apresentam baixa permeabilidade ao vapor d'água. Os resultados de FTIR evidenciaram que não ocorrem interações químicas entre o biopolímero e o plastificante na formação dos biofilmes.
\end{abstract}

\section{INTRODUÇÃO}

O tempo de prateleira é uma importante característica de todos os alimentos e engloba o período desde sua produção e embalagem até o momento em que se tornam inaceitáveis para consumo (FORSYTHE, 2002).

Embalagens alimentares têm como principal função proteger os alimentos da deterioração, principalmente microbiológica e oxidativa, aumentando seu tempo de prateleira. As embalagens plásticas de origem petroquímica são as mais utilizadas para esse fim. Isto deve-se ao fato de estarem disponíveis em larga escala e a baixo custo, além de aliarem propriedades como resistência mecânica e barreira a gases e aromas (THARANATHAN, 2003).

Por causa da grande estabilidade estrutural, resistência química, física, à deterioração microbiológica e ainda as dificuldades relacionadas à reciclagem de materiais sintéticos, o grande volume de lixo produzido após o descarte destas embalagens pode tornar-se um grande problema ambiental. Assim tem sido despertado o interesse em pesquisas que apliquem materiais biodegradáveis que desempenhem a função de embalagens (MALI, GROSSMANN, YAMASHITA, 2010; 
SCHLEMMER, 2011). Surgem como alternativa, então, os biofilmes.

Biofilmes são materiais biodegradáveis produzidos basicamente a partir de biopolímeros capazes de formar uma matriz contínua. Sua aplicação em embalagens está diretamente relacionada com suas características e as possíveis interações com o produto e o ambiente (CARVALHO, 1997).

A aplicação deste tipo de embalagens para alimentos é, contudo, restrita, por causa de suas propriedades mecânicas e de barreira inferiores (SORRENTINO, GORRASI, VITTORIA, 2007), sendo o grande desafio em sua implementação a escolha da matriz polimérica utilizada, de acordo com as propriedades que se deseja conferir ao alimento.

Os principais componentes de nossa alimentação atual, como proteínas, carboidratos e lipídeos, preenchem os requisitos para preparação de biofilmes e podem ser utilizados individualmente ou combinados para formar filmes que não alterem o sabor do alimento (PAVLATH, ORTS, 2009).

No caso das proteínas, ambas, de origem animal ou vegetal, podem ser utilizadas na formação de filmes e coberturas, a partir de soluções contendo três principais componentes, nomeadamente: proteína, plastificante e solvente (DANGARAN, TOMASULA, QI, 2009).

O colágeno é uma proteína fibrosa encontrada em todo o reino animal. Contém cadeias peptídicas dos aminoácidos glicina, prolina, lisina, hidroxilisina, hidroxiprolina e alanina. Essas cadeias são organizadas de forma paralela a um eixo, formando as fibras de colágeno, que proporcionam resistência e elasticidade à estrutura presente (SILVA, PENNA, 2012).

A gelatina é o produto da desnaturação do colágeno de origem animal, como bovina, suína ou de peixes, e tem sido mundialmente utilizada para produção de alimentos, materiais médicos e meios de cultura de microorganismos (YOSHIMURA et al., 2000). Contém aminoácidos unidos por ligações peptídicas e consiste, predominantemente, dos seguintes: glicina (33\%), prolina e hidroxiprolina (20\%), além de alanina (11\%) (ROGERS, 2001).

Há que se levar em conta que filmes elaborados a partir de proteínas apresentam boas propriedades mecânicas, ópticas e sensoriais, embora sejam sensíveis à umidade e apresentem elevada permeabilidade a vapor de água (FAKHOURI et al., 2007). Apesar disto, a gelatina apresenta-se como uma interessante alternativa para a produção de filmes para aplicações alimentares.

Desta forma, o objetivo deste trabalho foi desenvolver e caracterizar biofilmes à base de gelatina e avaliar sua espessura média, bem como permeabilidade ao vapor de água, associando-as às características químicas de sua estrutura molecular, através de espectros FTIR-ATR.

\section{MATERIAIS E MÉTODOS}

$\mathrm{Na}$ preparação das soluções filmogênicas foram utilizados: gelatina comercial como matriz polimérica, glicerol como plastificante e água como solvente. Esta escolha deveu-se ao fato de que Ricardo (2014), em análises preliminares de biofilmes produzidos com diferentes biopolímeros, obteve resultados que apontaram aqueles à base de gelatina e glicerol como os com melhores propriedades para fins de aplicação em alimentos.

As soluções foram preparadas adicionando-se gelatina na proporção de $1 \mathrm{~g}$ de sólido seco, 0,3 g de plastificante e $100 \mathrm{~mL}$ de solvente.

Os filmes foram obtidos pela metodologia de casting em triplicatas. A Figura 1 apresenta a metodologia empregada na obtenção dos filmes. 
Figura 1 - Metodologia de obtenção dos filmes.

Pesagem do polímero e do plastificante

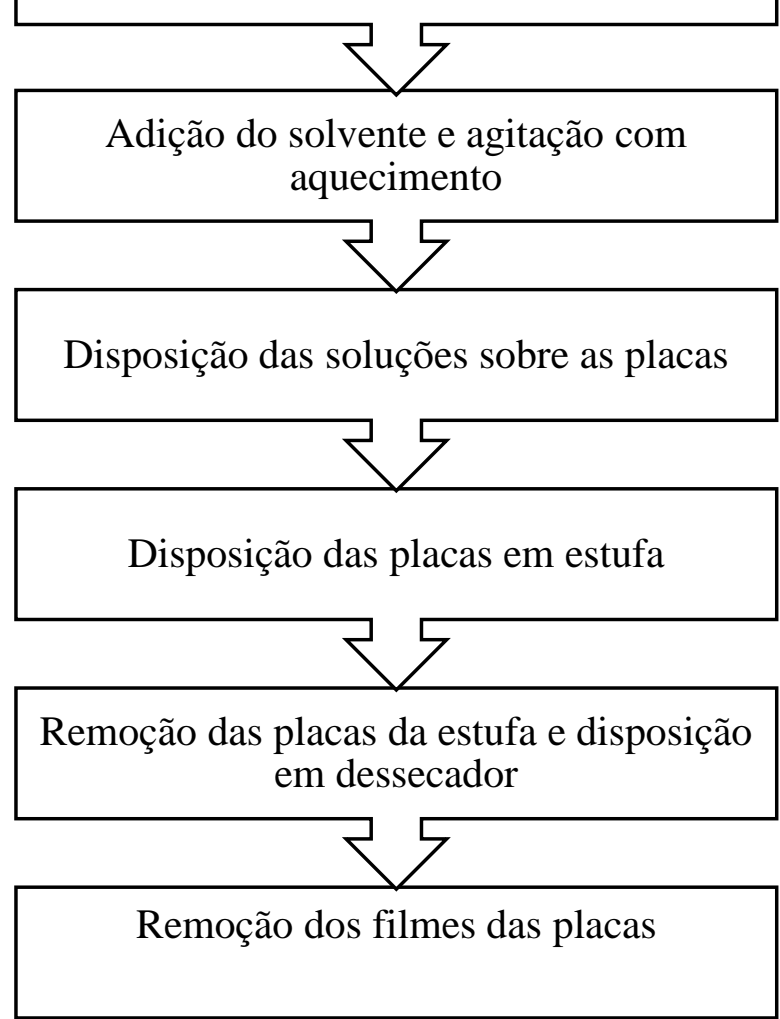

Fonte: Autor (2015).

Após a pesagem do polímero e do plastificante, adicionou-se o solvente e submeteu-se, então, a mistura a agitação em agitador magnético com aquecimento, à temperatura de $70{ }^{\circ} \mathrm{C}$ e $1100 \mathrm{rpm}$ até que ocorresse a gelatinização do polímero e formação das soluções filmogênicas.

Em seguida, as soluções foram vertidas em placas de acrílico de $15 \mathrm{~cm}$ de diâmetro e levadas à estufa, a $40{ }^{\circ} \mathrm{C}$, por $24 \mathrm{~h}$, para evaporação do solvente. Após este período, as placas foram removidas e dispostas em dessecador por $24 \mathrm{~h}$. A seguir, retiraram-se os filmes das placas, submetendo-os às análises propostas.

Para caracterizar a espessura média de cada filme foram realizadas 10 medidas em pontos distintos e aleatórios utilizando um paquímetro digital.

A análise de permeabilidade ao vapor de água foi conduzida segundo o método utilizado por Moura (2012), método padrão E0096-00 (ASTM, 2000). As amostras foram cortadas em forma de discos de diâmetro 50 $\mathrm{mm}$, fixadas em células de permeação de alumínio contendo cloreto de cálcio anidro $\left(\mathrm{CaCl}_{2}\right)$ granulado, e por fim, acondicionadas em dessecador a $25{ }^{\circ} \mathrm{C}$ e $75 \%$ de umidade relativa. A partir do ganho de massa do $\mathrm{CaCl}_{2}$ granulado, mensurado em intervalos de $24 \mathrm{~h}$ durante 7 dias, foi possível determinar o vapor de água transferido através do filme. A Figura 2 mostra, esquematicamente, o método empregado para esta análise.

\section{Figura 2 - Metodologia para análise de PVA.}

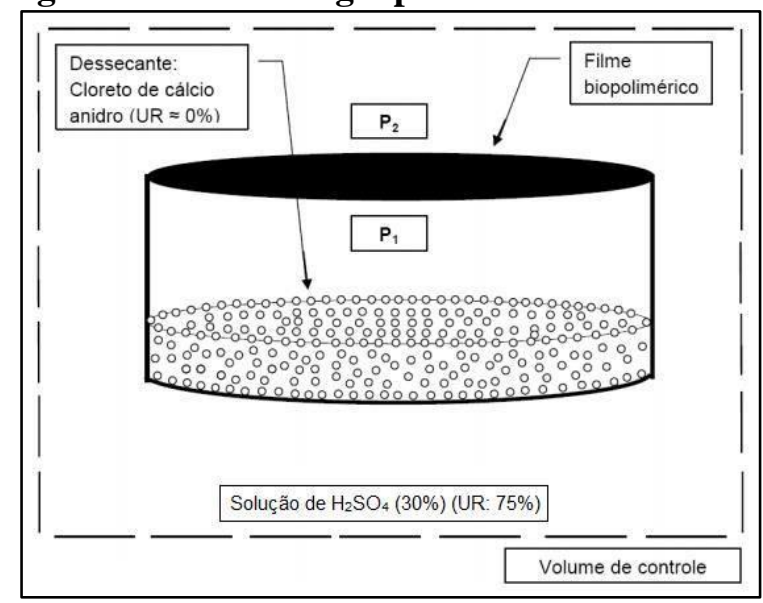

Fonte: Souza (2009).

A Equação 1 foi utilizada para quantificar a permeabilidade ao vapor de água dos filmes.

$P V A=\frac{m_{a b}}{t} \frac{L}{A \Delta P}$

Em que PVA é a permeabilidade ao vapor de água (g.mm. $\left.\mathrm{kPa}^{-1} \cdot \mathrm{dia}^{-1} \cdot \mathrm{m}^{-2}\right), \mathrm{m}_{\mathrm{ab}}$ a massa de umidade absorvida ( $\mathrm{g}), \mathrm{t}$ o tempo total do teste (dias), L a espessura do filme ( $\mathrm{mm}), \mathrm{A}$ a área da superfície exposta do filme $\left(\mathrm{m}^{2}\right)$ e $\Delta \mathrm{P}$ a diferença de pressão parcial através do filme (Pa). 
A fim de saber informações sobre as estruturas químicas da amostra e se ocorrem mudanças moleculares causadas pela adição de plastificante, através das vibrações e estiramentos das moléculas constituintes do biofilme, foi realizada análise de Espectroscopia de Infravermelho com Transformada de Fourier (FTIR) dos filmes de gelatina e do biopolímero utilizado em sua composição.

Para tanto, utilizou-se espectrômetro Perkin-Elmer através da técnica de Refletância Total Atenuada (ATR) no intervalo de 500 a $4000 \mathrm{~cm}^{-1}$, com 16 varreduras por espectro e resolução de $4 \mathrm{~cm}^{-1}$. As amostras de cada filme foram cortadas em pequenos quadrados enquanto que as de gelatina pura foram maceradas e, então, inseridas no porta amostras do aparelho FTIR-ATR, para obtenção dos espectros a serem analisados.

\section{RESULTADOS E DISCUSSÃO}

A Figura 3 apresenta os biofilmes obtidos após a remoção das placas de acrílico.

Figura 3 - Biofilmes após secagem do solvente.

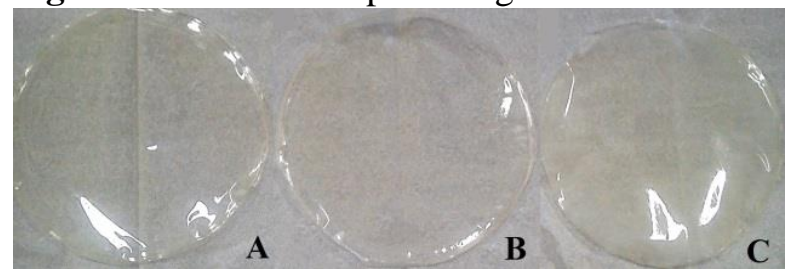

Fonte: Autor (2015).

Davanço (2007) relata que filmes e coberturas proporcionam aos alimentos naturais um aspecto mais atrativo e aumentam sua vida útil. Assim, da Figura 3, observa-se que os filmes obtidos, transparentes e brilhantes, possuem potencial de valorizar a aparência do produto recoberto.

$O$ resultado para a análise de espessura foi de 0,04 $\pm 0,01 \mathrm{~mm}$. Este valor mostra que a metodologia de elaboração dos filmes foi adequada, pois obteve-se valores de espessura semelhantes aos de autores que também analisaram filmes biodegradáveis, como Oliveira e Cavalcanti (2007) que encontraram $0,09 \pm 0,01 \mathrm{~mm}$ e Fakhouri et al. (2007), $0,063 \pm 0,002 \mathrm{~mm}$.

$\mathrm{O}$ resultado para a análise da permeabilidade ao vapor d'água (PVA) foi de $2,41 \pm 0,37$ g.mm.kPa ${ }^{-1} \cdot \mathrm{dia}^{-1} \cdot \mathrm{m}^{-2}$. Santos (2012) encontrou valores semelhantes: 2,21 \pm 0,3 g.mm $\cdot \mathrm{kPa}^{-1} \cdot \mathrm{dia}^{-1} \cdot \mathrm{m}^{-2}$ para biofilmes de gelatina preparados com água destilada e sem adição de plastificante. Moura et al. (2012), produziram biofilmes de quitosana e glicerol, na proporção 75:25 e encontraram uma permeabilidade de 7,84 $\pm 0,08$ g.mm.kPa ${ }^{1} \cdot \mathrm{dia}^{-1} \cdot \mathrm{m}^{-2}$, maior que a permeabilidade encontrada neste trabalho.

A Figura 4 apresenta os espectros das bandas características da gelatina pura e dos biofilmes estudados.

Figura 4 - Espectro FTIR-ATR dos biofilmes.

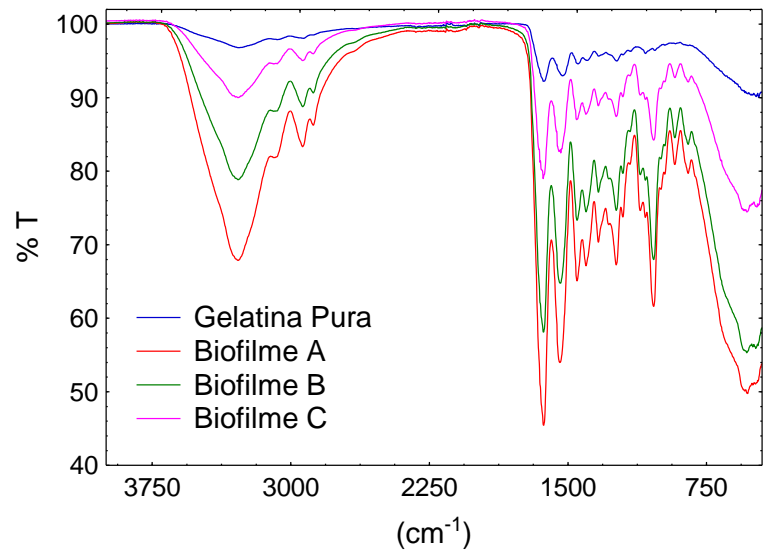

Fonte: Autor (2015).

O espectro infravermelho de uma proteína é decorrente das absorções do grupo peptídico (bandas de amida I, II, III), sendo que a amida I é responsável pela maior quantidade de informações sobre as estruturas secundárias das proteínas.

A partir da Figura 4 observa-se que ambas as amostras apresentam picos na banda de aproximadamente $3300 \mathrm{~cm}^{-1}$; a banda 
intensa, larga e centrada é devida principalmente ao estiramento do grupo $\mathrm{N}-\mathrm{H}$ característico de uma amida (OSIRO, FRANCO, CONALGO, 2000). Também nesta faixa encontram-se bandas características de hidroxila presentes na molécula de glicerol (MATTOS, 2014).

Segundo Reis et al. (2011), o glicerol é uma molécula pequena, de baixa volatilidade, que causa o aumento de flexibilidade, extensibilidade e distensibilidade, seguidas por diminuição na resistência mecânica e temperatura de transição vítrea do biopolímero, quando utilizado como plastificante.

Os picos entre, aproximadamente, 1633 $\mathrm{cm}^{-1}$ e $1525 \mathrm{~cm}^{-1}$ são característicos das amidas I e II, respectivamente. Para a amida I, tem-se estiramento da carbonila $(\mathrm{C}=\mathrm{O})$ e para a amida II vibrações no plano da ligação N-H e estiramento C-N, característicos da glicina (PEDROSO, 2009). Segundo D'Avila (2010), como tanto o grupo carbonila quanto o grupo amino, estão envolvidos em ligações de hidrogênio responsáveis pela manutenção de estruturas secundárias, as posições de ambas as regiões da amida I e amida II são sensíveis às alterações estruturais das moléculas proteicas.

Segundo Lacerda, Pleipis e Goissis (1998) e Bet, Goissis e Lacerda (2001), a banda em $1236 \mathrm{~cm}^{-1}$, tem as vibrações no plano da amida III devido ao estiramento C-N e a deformação $\mathrm{N}-\mathrm{H}$, que é sensível às alterações na estrutura secundária da hélice tríplice, enquanto a banda $1446 \mathrm{~cm}^{-1}$ corresponde às vibrações dos anéis pirrolidínicos de prolina e hidroxiprolina, que ao contrário do pico da amida III, tem sua intensidade independente das variações estruturais da matriz do colágeno. A hidroxiprolina é um dos aminoácidos responsáveis pela manutenção da estabilidade da hélice tríplice. Uma menor quantidade desta faz com que o colágeno perca a conformação de hélice tríplice quando submetida à elevação da temperatura, o que prejudica a propriedade de gelificação (GÓMEZ-GUILLÉN et al., 2002).

Os espectros demonstraram que não houve interação química entre a gelatina e o plastificante. Isto pode ser visto uma vez que a ocorrência dos picos nos espectros da gelatina pura e dos biofilmes se mantiveram, apenas alterando sua intensidade. Andreuccetti (2010) analisou formulações de biofilmes de gelatina com diferentes plastificantes e conclui que as análises de FTIR não mostraram evidências de interações adicionais entre o plastificante e o polímero. $\mathrm{Ou}$ seja, o plastificante interagiu fisicamente com a matriz polimérica concedendo-lhe flexibilidade, possibilitando o aumento da vibração e estiramento molecular e implicando em picos mais intensos.

Tendo em vista que os picos característicos da glicina $\left(1525 \mathrm{~cm}^{-1}\right)$ foram observados nos três filmes, bem como na gelatina pura, e que ela está associada à resistência e elasticidade da estrutura proteica, constatou-se que não houve mudanças na estrutura da gelatina após a formação dos biofilmes.

Conforme Prestes et al. (2013) a hidroxiprolina está ligada à propriedade de gelificação da gelatina. $O$ fato de seu pico característico $\left(1446 \mathrm{~cm}^{-1}\right)$ aparecer após a formação dos biofilmes, justifica a utilização da gelatina na produção dos mesmos.

\section{CONCLUSÃO}

Os filmes obtidos apresentaram aspecto visual atrativo para recobrimento de alimentos. A espessura média dos biofilmes foi de 0,04 $\pm 0,01 \mathrm{~mm}$, demonstrando que a metodologia de preparo foi adequada.

As análises de PVA resultaram em uma permeabilidade de 2,41 $\pm 0,37$ g.mm.kPa-1.dia-1.m-2, comprovando que a gelatina é uma boa opção quando se deseja 
obter filmes com baixa permeabilidade a vapor d'água.

Os resultados obtidos para as análises de espectros demonstraram que não houve interação química entre as moléculas do polímero e do plastificante. Constatou-se, todavia, que eles interagiram fisicamente resultando em uma maior mobilidade da cadeia polimérica sem que ocorressem alterações na estrutura química da mesma.

Por tudo isso, a gelatina é um biopolímero adequado a ser utilizado na formação de biofilmes, principalmente quando se deseja revestimentos flexíveis e que forneçam propriedades de barreira a vapor d'água.

\section{REFERÊNCIAS}

ANDREUCETTI, C. Desenvolvimento e caracterização de filmes biodegradáveis a base de gelatina, plastificantes hidrofóbicos e surfactantes naturais. Tese (Doutorado em Alimentos e Nutrição). 2010. 241 p. Universidade Estadual de Campinas, Faculdade de Engenharia de Alimentos, Campinas, 2010.

ASTM. Standard methods of water vapor transmission of materials. Método: E0099600. In: ASTM manual book of ASTM standards, p. 907-914. Philadelphia: American Society for Testing and Materials, 2000.

ASSIS, O. B. G.; LEONI, A. M. Filmes comestíveis de quitosana: ação biofungicida sob frutas fatiadas. Biotecnologia, Ciência \& Desenvolvimento, Brasília, v.6, n. 30, p. 3338, 2003.

BET, M. R.; GOISSIS, G.; LACERDA, C. A. Characterization of Polyanionic collagen prepared by selective hydrolysis of asparagine and glutamine caboxyamide side chains.
Biomacromolecules, v.2, p. 1074-1079, 2001.

CARVALHO, R. A. Desenvolvimento e caracterização de biofilmes à base de gelatina. 1997. 143 p. Tese (Mestrado em Engenharia de Alimentos). Universidade Estadual de Campina, Campinas, 1997.

DANGARAN, K.;TOMASULA, P. M.; QI, P. Structure and Function of Protein-Based Edible Films and Coatings. In: Edible Films and Coatings for Food Applications. New York: Springer Science and Business Media, 2009.

DAVANÇO, T. Desenvolvimento e caracterização de biofilmes à base de gelatina, triacetina, ácido esteárico ou ácido capróico e surfactantes. Dissertação (Mestrado em Alimentos e Nutrição). 2006. 155 p. Universidade Estadual de Campinas, Campinas, 2006.

D'AVILA, V. D. L. Biofilmes à base de gelatina, aplicados na conservação de frutos de mirtilo (Vaccinium ashei Reade). Dissertação (Mestrado em Ciência dos Alimentos). 2010. 117 p. Universidade Federal de Santa Catarina, Florianópolis, 2010 .

FAKHOURI， F. M.; FONTES， L. C.; GONÇALVES, P. V. M.; MILANEZ, C. R.; STEEL, C. J.; COLLARES-QUEIROZ, F. P. Filmes e coberturas comestíveis compostas à base de amidos nativos e gelatina na conservação e aceitação sensorial de uvas Crimson. Ciência e Tecnologia de Alimentos, v. 27, n. 2, p. 369-375, abr./jun. 2007.

FORSYTHE, S. J. Microbiologia da Segurança Alimentar. Artmed: Porto Alegre, 2002. Tradução: Maria Carolina Minardi Guimarães e Cristina Leonhardt. 
GOMES-GUILLÉN， M. C.; TURNAY，J.; FERNANDEZ-DIAS, M. D.; ULMO, N.; LIZARBE, M. A.; MONTERO, P. Structural and physical properties of gelatin extracted from different marine species: a comparative study. Food Hydrocolloids, v.16, p.25-34, 2002.

LACERDA， C.; PLEIPIS， A. M. G.; GOISSIS, G. Hidrólise seletiva de carboxiamidas de resíduos de asparagina e glutamina em colágeno: preparação e caracterização de matrizes aniônicas para uso como biomateriais. Química Nova, v.21, n.3, p. 267-271, 1998.

MALI, S.; GROSSMANN, M. V. E.; YAMASHITA, F. Filmes de amido: produção, propriedades e potencial de utilização. Semina: Ciências Agrárias, Londrina, v. 31, n. 1, p. 137-156, jan./mar. 2010.

MATTOS, A. P. Caracterização termoquímica do glicerol bruto $\mathrm{e}$ aproveitamento energético da queima do glicerol em uma planta de médio porte de produção de biodiesel. 2014. 184 p. Tese (Mestrado em Engenharia Mecânica), Universidade Federal de Itajubá, Itajubá, 2014.

MOURA, C. M. Estudo do processo de produção de quitosana e seu uso na obtenção de filmes biopoliméricos. 2012. 153 p. Tese (Doutorado em Engenharia e Ciência de Alimentos). Universidade Federal do Rio Grande, Rio Grande, 2012.

MOURA, C. M.; MOURA, J. M.; SANTOS, J. P.; KOSINSKI, R. C.; DOTTO, G. L.; PINTO, L. A. A. Evaluation of Mechanical Properties and Water Vapor Permeability in Chitosan Biofilms Using Sorbitol and
Glycerol. Macromolecular Symposia, v. 319, p. 240-245, 2012.

OLIVEIRA, F. M.; CAVALCANTI, O. A. Pré-Bióticos na Formação de Filmes Isolados de Eudragit ${ }^{\circledR}$ RS 30 D. Avaliação das Propriedades de Intumescimento e Permeabilidade. Latin American Journal of Pharmacy, v. 26, n. 3, p. 325-331, 2007.

OSIRO, D.; FRANCO, R.W. A.; COLNAGO, L. A.; Spectroscopic Characterization of the Exopolysaccharide of Xanthomonas axonopodis pv. citri in $\mathrm{Cu} 2+$ Resistance Mechanism. Journal of Brazilian Chemical Society, v. 22, n.7, 2011.

PAVLATH, A. E.; ORTS, W. Edible Films and Coatings: Why, What, and How? In: EMBUSCADO, M. E.; HUBER, K. C. Edible Films and Coatings for Food Applications. New York: Springer Science and Business Media, 2009.

PEDROSO, M. G. V. Estudo Comparativo de Colágeno hidrolisado e comercial com adição de PVA. 2009. 71p. Dissertação (Mestrado em Químicia Analítica). Universidade de São Paulo, São Carlos, 2009.

PRESTES, R. C.; GOLUNSKI， S. M.; TONIAZZO, G.; KEMPKA, A. P.; LUCCIO, M. CARACTERIZACAO DA FIBRA DE COLAGENO, GELATINA E COLAGENO HIDROLISADO. Revista Brasileira de Produtos Agroindustriais, Campina Grande, v.15, n.4, p.375-382, 2013.

REIS， L. C. B. ; BARCELLOS, A. D. ; MACHADO, B. A. S. ; DRUZIAN, J. I. FILME BIODEGRADÁVEL INCORPORADO COM GLICEROL E ADITIVOS NATURAIS. Cadernos de Prospecção - ISSN 1983-1358, vol. 4, n. 4, p.23-32, 2011. 
RICARDO, L. P. Elaboração e análise de filmes biopoliméricos à base de gelatina $\mathrm{e}$ amido para produtos naturais. 2014. 42p. Trabalho de Conclusão de Curso (Bacharelado em Engenharia Química). Universidade Federal do Pampa, Bagé, 2014.

ROGERS, M. D. H. Rheological properties of gelatin/starch composite gels. $2001.90 \mathrm{p}$. Tesis (Master of Science). University of Guelph, Canada, 2001.

SANTOS, J. P.; HOFFMANN, H. P; BANDEIRA, S. F., MOURA, C. M.; PINTO, A. A. Avaliação das propriedades mecânicas e permeabilidade ao vapor de água em filmes biopoliméricos de gelatina incorporando quitosana. In: Química dos Alimentos, 2012, Recife. Anais do $5^{\circ}$ Congresso Brasileiro de Química, Recife, 14-18 out. 2012.

SCHLEMMER, D. Estudo das propriedades de nanocompósitos amido montimorilonita, utilizando óleos vegetais como plastificantes. 2011. 160 p. Tese (Doutorado em Química). Universidade Federal de Brasília, Brasília, 2011.

SILVA, T.F.; PENNA, A. L. B. Colágeno: Características químicas e propriedades funcionais. Revista Instituto Adolfo Lutz, São Paulo, v.71, n. 3, p. 530-539, 2012.

SORRENTINO, A.; GORRASI, G.; VITTORIA, V. Potential perspectives of bionanocomposites for food packaging and applications. Trends in Food Science and Technology, v. 18, p. 84-95, 2007.

THARANATHAN, R. N. Biodegradable films and composite coatings: past, presente and future. Trends in Food Science and Technology, v. 14, p. 71-78, 2003.

YOSHIMURA, K. ; TERASHIMA, M. ; HOZAN, D. ; EBATO, T. ; NOMURA,
Y. ;ISHII, Y. ;SHIRAI, K. Physical Properties of Shark Gelatin Compared with Pig Gelatin. Journal of Agricultural and Food Chemistry, v. 48, p. 2023-2027, 2000.

\section{AGRADECIMENTOS}

Agradecemos à Unipampa Universidade Federal do Pampa, pelo espaço cedido para realização deste trabalho. Ao CNPq e à FAPERGS pela concessão das bolsas de Iniciação Científica. Ao Dr. Flávio André Pavan, pelo auxílio nas análises de FTIR-ATR. 